\title{
Heterogeneity in risk and safety perceptions of international tourists
}

\author{
Cláudia Seabra ${ }^{\mathrm{a}, *, 1}$, Sara Dolnicar ${ }^{\mathrm{b}, 2}$, José Luís Abrantes ${ }^{\mathrm{a}, 1}$, Elisabeth Kastenholz ${ }^{\mathrm{c}, * *}$ \\ ${ }^{a}$ Polytechnic Institute of Viseu, Campus Politécnico de Repeses, 3504-510 Viseu, Portugal \\ ${ }^{\mathrm{b}}$ Institute for Innovation in Business and Social Research, University of Wollongong, Wollongong, 2522 NSW, Australia \\ ${ }^{\mathrm{c}}$ Aveiro University, DEGEI, Campus Universitário de Santiago, 3810-119 Aveiro, Portugal
}

\section{H I G H L I G H T S}

- We did a data-driven segmentation study about tourists' perceived risks.

- There is heterogeneity among tourists in their behaviors and risk perceptions.

- International tourists can be segmented in 7 distinct clusters.

- The clusters differ in amounts and types of risk perceptions.

\section{A R T I C L E I N F O}

\section{Article history:}

Received 7 December 2011

Accepted 11 September 2012

\section{Keywords:}

International tourism

Travel decision making

Market segmentation

Perceived risk

Hofstede

\begin{abstract}
A B S T R A C T
The travel decisions of international tourists have, over the past decade, been significantly affected by external events, such as the fear of pandemics and terrorist attacks. Yet, little attention has been paid to heterogeneity among tourists with respect to risk perceptions. The question whether some tourist segments are less sensitive to external risks and thus more attractive to tourism industry in times of crises remains largely unanswered. This study conducts a data-driven segmentation of heterogeneity in the tourist population with respect to perceived risks of international travel and assesses if market segments with different risk perception patterns are distinct in other behavioral and personal characteristics. Additionally the study includes nationality as a proxy for "cultural background", here analyzed in light of Hofstede's (1983) model. Practical implications are discussed.
\end{abstract}

(C) 2012 Elsevier Ltd. All rights reserved.

\section{Introduction}

Globalization of tourist markets has increased over recent years (Levitt, 1983), contributing to the escalation of global risks. Tourism is viewed as one of the activities most susceptible to global risk factors (Ritchie, 2004). Recent historical examples include political instability and war in Egypt and Tunisia, health threats such as influenza, as well as crime, violence, and terrorism felt globally after the September 11 attacks in the US, and the natural disasters in Japan and Thailand (Coshall, 2003; Fuchs \& Reichel, 2006; Kozak, Crotts, \& Law, 2007; Lepp \& Gibson, 2003). Even minor crises in one part of the world may trigger strong reactions in other areas.

\footnotetext{
* Corresponding author. Tel.: +351 965660080; fax: +351 232424651.

** Corresponding author. Tel.: +351 234370 026; fax: +351 234370215 .

E-mail addresses: cseabra@dgest.estv.ipv.pt, cseabra@estv.ipv.pt (C. Seabra), sara_dolnicar@uow.edu.au (S. Dolnicar), jlabrantes@ipv.pt (J.L. Abrantes), elisabethk@ua.pt (E. Kastenholz).

1 Tel.: +351232480 500; fax: +3512324424651.

2 Tel.: +612 4221 3862; fax: +6124221 4154 .
}

Tourism, especially international tourism, is highly sensitive to safety and security issues (Pizam \& Mansfeld, 1996). It is one of the activities most vulnerable to changes in the world stage that may produce modifications in tourist behavior (Coshall, 2003; Dimanche \& Leptic, 1999; Levantis \& Gani, 2000; Pizam \& Mansfeld, 1996). Safety concerns strongly influence tourists' decision-making processes (Beirman, 2002; Crompton \& Ankomah, 1993; Fesenmaier, 1988; Moutinho, 2000; Woodside \& King, 2001; Woodside \& Lysonski, 1989). Travelers select destinations that best match their needs, offer the most benefits, and have the lowest possible costs or risks. If a tourist feels insecure or threatened at a specific destination, an overall negative impression is likely to result (George, 2003). Consequently, destinations perceived as being safer may be preferred, and those perceived as risky or unsafe may be rejected (Beirman, 2002; Gu \& Martin, 1992; Mansfeld, 1996; Sönmez, 1998).

Travelers' risk perceptions about their personal safety have a major impact on patterns of tourism demand. Safety should be recognized as one of the most fundamental conditions for the development of tourism destinations (Fletcher \& Morakabati, 2008). Unsafe destinations will have difficulties in attracting tourists (Beirman, 2003; George, 2003; Prideaux, 1996; Rittichainuwat \& Chakraborty, 2009; 
Sönmez \& Graefe, 1998a), and a negative image due to the perceived lack of security may seriously damage the local tourism industry (Goodrich, 2002; Lepp \& Gibson, 2003; Pizam, 2002). Additionally, risk associated with some countries because of incidents in neighboring countries can produce devastating effects in entire regions (Lepp \& Gibson, 2003) through the "effect of generalization." Therefore, we need to recognize the market's vulnerability in order to prevent major drops in demand when negative external events occur. A clearer understanding of the traveler's decision-making process and the role of intervening variables are required, especially regarding travel inhibitors (Quintal, Lee, \& Soutar, 2010), such as risk perception, in order to help formulate improved destination development or recovery strategies (Chen, 1997). Creating conditions for tourists to feel safe before and during the trip may be critical to the success of a destination competing internationally (Huan \& Beaman, 2004).

Studies on risk and safety perception have grown exponentially (Fuchs \& Reichel, 2006), with several showing the negative impacts of perceived risk on tourism (Coshall, 2003). Possibly as a consequence, items related to risk and safety are increasingly being included in destination image assessment instruments (Sönmez \& Graefe, 1998b). However, despite an acknowledgment of the importance of perceived risk, very few approaches have been suggested that proactively deal with perceived risk. For example, market segments could be identified which are less concerned with potential risks, and may thus react less negatively in troubled times (Dolnicar, 2005, 2007). In order to assess if such a market segment exists, we need to gain some insight into the heterogeneity within the international tourism market regarding perceived risk. This is the aim of the present study.

This paper specifically investigates the following research issues for the first time. It provides an empirical investigation of heterogeneity among international tourists regarding risk perception patterns; and then offers a description of the significant differences between market segments with different risk perception patterns.

\section{Literature review}

Bauer (1967) was one of the first to suggest that consumer behavior is an act of risk, because any individual action of consumption is associated with uncertainty, implying unanticipated - and possibly unpleasant - consequences. Most researchers have studied perceived risk, rather than objective or real risk (Bauer, 1967), because ultimately, perceived risk determines behaviors (Bauer, 1967; Budesco \& Wallstein, 1985). However, the past 50 years of study on risk perception reveal difficulties in operationalizing this concept (Rohel \& Fesenmaier, 1992). Jacoby and Kaplan (1972), Kaplan, Szybillo, and Jacoby (1974) suggest a multi-attribute model of risk, where several product attributes are judged separately by each consumer. When the consumer perceives a failure in one of the product attributes, this leads to a generalized feeling of loss.

Risk perceptions are specific to each situation (Dowling, 1986; Gemunden, 1985), and should therefore be evaluated using measurement instruments appropriate to the decision-making context. Also, some researchers have argued that an individual evaluating a situation pays more attention to some risk dimensions than to others, depending on the particular decision-making process (Rohel \& Fesenmaier, 1992).

Differences exist between perceived risks for physical goods compared to services (Havlena \& DeSarbo, 1990), specifically services in the leisure domain (Cheron \& Ritchie, 1982). All types of risk are perceived as more pronounced in the service context when compared to tangible goods (Murray \& Schlater, 1990). Purchasing tourism services implies a high level of perceived risk (Hugstad, Taylor, \& Bruce, 1987), because of tourism's intangible nature, and the fact that consumption and production occur simultaneously, means that the items offered are therefore poorly standardized (Zeithaml, 1981). Tourism services are typically purchased at a geographical - but also temporal, and even cultural - distance (Kastenholz, 2010). Additionally, tourists are complex consumers who do not necessarily maximize the utility of their choices'; they do not always evaluate all possible options, because tourism decisions depend on context and the person making the decision (van Middelkoop, Borgers, \& Timmermans, 2003). Tourism consumption is emotional, and refers to idealized experiences that generally involve a prolonged planning process leading to destination choice. For an extensive evaluation and comparison of alternatives, the tourism decision-making process typically involves a series of individuals (Decrop \& Snelders, 2004; Seabra, Abrantes, \& Lages, 2007). Tourists make their travel choices with no expectation of economic or material return; instead, they expect intangible results, such as pleasure and satisfaction (Moutinho, 1987). However, some tangible aspects of travel can contribute to risk perception. For instance, when deciding on the tourism destination, the choice of transport mode is closely connected with that decision (Dellaert, 1995 in van Middelkoop et al., 2003). The chosen travel mode further affects the already complex tourism decisionmaking process (van Middelkoop et al., 2003). Distance and subsequent time required to travel (Eugenio-Martin, 2003), past experience, comfort, and travel conditions (such as flexibility, weather conditions) (Nerhagen, 2003) also influence the choice of travel mode. Traveling by air, for instance, can represent an additional perceived risk for the tourist. The main reasons that lead to an overestimation of risk perception associated with flying are the perceived lack of control and the seriousness of the risk involved, higher associated price, and the large media coverage of flight incidents and accidents (see Carlsson, Johansson-Stenman, \& Martinsson, 2004).

Older studies on leisure regarding risk perception are based on scales developed in the marketing of tangible products (Jacoby \& Kaplan, 1972). However, tourism researchers argue that the relationship between risk perceptions and travel behavior are travel specific and context dependent, requiring specifically elaborated scales for their evaluation (Dolnicar, 2005; Reisinger \& Mavondo, 2005; Sönmez \& Graefe, 1998b).

Risk perception in tourism is associated with a multiplicity of factors. The first studies on risk perception in the leisure field adopted the five risk dimensions suggested by Jacoby and Kaplan (1972): psychological (how the purchase may affect what we think about ourselves); social (how the purchase may affect what the others think of us); financial (the amount of expenses compared to the level of income and perceptions of the value of money); time (the planning, purchase execution and opportunity cost of time); and physical (how the purchase may affect our physical and psychological wellbeing) (for example, Cheron \& Ritchie, 1982; Mitra, Reiss, \& Capella, 1999; Stone \& Gronhaug, 1993). Later, further risk dimensions were added, including risk of time (for example, Roselius, 1971; Stone \& Gronhaug, 1993) and risk of satisfaction (Cheron \& Ritchie, 1982). The resulting seven dimensions were used in Roehl and Fesenmaier's study (1992). Recent studies include the dimensions political instability/unrest (see Seddighi, Nuttall, \& Theocharous, 2001; Sönmez \& Graefe, 1998b), health, and terrorism (Sönmez \& Graefe, 1998a, 1998b).

Besides the conceptualization of perceived risk, past research has also identified internal personal factors that determine how strongly an objective risk is perceived by a person, and these reveal a diversity of relevant factors: personality traits (Reisinger \& Mavondo, 2005; Rohel \& Fesenmaier, 1992); culture and nationality (Hofstede, 1983; Hurley, 1988; Kastenholz, 2010; Kozak et al., 2007; Reisinger \& Mavondo, 2006; Seddighi et al., 2001); past 
experience, where experienced tourists feel less risk (Lepp \& Gibson, 2003; Sönmez \& Graefe, 1998a, 1998b); demographics, namely age (Gibson \& Yiannakis, 2002; Lepp \& Gibson, 2003); gender (Lepp \& Gibson, 2003); income and education (Floyd \& Pennington-Gray, 2004; Mitchell \& Vassos, 1997; Sönmez \& Graefe, 1998a); everyday contact with crime and violence (Brunt, Mawby, \& Hambly, 2000; Milman \& Bach, 1999); and travel motivations, where benefits are sought (and perceived as offered by the destination) that outweigh perceived risks when taking the final decision (Sönmez \& Graefe, 1998b).

In the context of the international travel market, the variable nationality has been widely used to distinguish markets, consumer behaviors and corresponding marketing strategies, assuming a predominant role of "national culture" (Crotts \& Erdmann, 2002; Money \& Crotts, 2003). The present study analyzes the relevance of nationality as a proxy of "cultural background," based on Hofstede's 1983 model, particularly considering the dimension "uncertainty avoidance." This model, initially developed to study the influence of values in the workplace (Hofstede, 1980), is increasingly used in cross-cultural consumer behavior research (Mueller, Palmer, Mack, \& McMullan, 2003) as well as in tourism research (Reisinger \& Crotts, 2010), where "uncertainty avoidance" is identified as a determinant of travel planning behavior (Money \& Crotts, 2003). The present study further contributes to this discussion.

Research undertaken in tourism includes segmentation approaches of the tourist market based on risk perceptions (see Dolnicar, 2005, 2007; Floyd \& Pennington-Gray, 2004; Lepp \& Gibson, 2003; Rohel \& Fesenmaier, 1992). Lepp and Gibson (2003) identify two tourist segments based on risk perception, referring to Cohen's (1972) original typology of four tourist roles. The "organized mass tourist" and the "independent mass tourist" are combined into one group that prefers familiarity with the destination and usually travels within an "environmental bubble." The "drifters" and the "explorers" are motivated by novelty. These two groups face and feel risk in very different ways. Those seeking higher levels of novelty perceive less risk than those who prefer familiarity. On the other hand, the risk dimensions are also distinct. Health, war and political instability, terrorism, and strange food are identified as relevant risks for the first group, while being considered less risky by "drifters" and "explorers" (Lepp \& Gibson, 2003).

One source of risk for the "organized mass tourist" may well be a source of (positively felt) excitement by the "drifter" (Elsrud, 2001). However, the risk associated with excitement seeking should not exceed the limits that can jeopardize individuals' actual safety and transform risk that can be a pleasure into suffering (Giddens, 1991). Risk seeking, in these cases, takes place in controlled environments within the limits required by tourist's need for safety (Élias \& Dunning, 2008; Kozak et al., 2007).

Dolnicar (2005) recognizes the need to develop a typology of tourists based on risk perception, and identifies four segments based on fears associated with travel: tourists with high levels of fear regarding travel; "overseas skeptics" (tourists who believe they are likely to be confronted with terrorist action or contract contagious diseases from exotic destinations or from undertaking activities with high levels of risk and excitement); the "thrill seekers" (tourists who develop risk feelings that are quite opposite from the aforementioned "overseas skeptics"); and tourists with very reduced fear of traveling. Dolnicar (2007) conducted an a priori (Mazanec, 2000) or "commonsense" (Dolnicar, 2004) segmentation study, which compares risk perception patterns across domestic and international travelers, as well as comparing two commonly targeted segments: culture tourists and adventure tourists. No a posteriori (Mazanec, 2000) or "data-driven" (Dolnicar, 2004) segmentation study of perceived risk patterns has been conducted to date.

\section{Methodology}

\subsection{The research setting}

Several studies analyze the concept of perceived risk in tourism (Moutinho, 1987; Rohel \& Fesenmaier, 1992). In the tourism context, risk is defined as the uncertainty experienced by tourists during the purchasing and consumption process of travel services and destination choice (Tsaur, Tzeng, \& Wang, 1997). Risk is also identified as a fundamental concern of international travelers (Yavas, 1990). The present study aims to evaluate the risk perceptions of these travelers and to identify heterogeneity in this group regarding risk perception. Specifically, the research setting focuses on international tourists ending their trips and returning home by plane.

\subsection{Survey instrument}

This study employed scales previously established in the literature (Floyd \& Pennington-Gray, 2004; Sönmez \& Graefe, 1998b) to develop the survey instrument. The survey was translated into three languages: Portuguese, French, and Spanish, and then backtranslated to English. Respondents were offered seven response options to indicate their level of perceived risk relating to a range of possible events (ranging from " 1 - very low" to " 7 - extremely high"). A pre-test was conducted with a sample of 30 international tourists, whose results were used to further refine the questionnaire.

\subsection{Data collection}

The final data was collected during the period from January 2009 to March 2009. Tourists who agreed to participate in the study were randomly selected in loco across three international airports: Madrid, Barajas, Lisbon, Portela and Milan, Malpensa. Only tourists who had undertaken an international trip were interviewed. Two of the study authors administered the questionnaires, explaining the aim of the study to respondents at the moment after they checked in for their return trip. The questionnaire was selfadministered, ensuring anonymity, and thus eliminating interviewer bias as well as the likelihood of socially desirable responses. To reduce other potential biases, data was collected on the last Friday, Saturday, and Sunday of each month from 5.00 am to 5.00 pm. Thus, at Barajas airport, Madrid, the data was collected in January; at Malpensa airport, Milan, in February; and at Portela airport, Lisbon, in March 2009. This ensured that business or leisure travelers were not the only persons interviewed. Potential respondents were also asked if they had sufficient time to complete the survey, in order to ensure that they would not be forced to rush through the questionnaire to catch their flight, which would have compromised data quality. A final sample of 600 valid responses was obtained, which was equally divided among the three international airports.

\subsection{Data}

The survey question used as the basis for the construction of data-driven segments asked respondents to assess their level of perceived lack of safety on a seven-point scale, with the endpoints verbalized as "very low risk" and "very high risk." Variables were binarized, combining the low-risk options and the middle option together, and the three high risk options together. While this approach is not optimal, the fact that international respondents were asked to complete a survey with seven answer options means that cultural response styles were almost certainly captured, which calls into question whether the exact response option is comparable 
across all respondents. Binarization does not entirely eliminate this problem, but it at least avoids overemphasis on scale endpoints, which are biased by cross-cultural response styles within both the positive and negative side of the scale. In addition, the binary data format allows the use of Euclidean distance in the clustering process, which is not a suitable approach for ordinal data.

Based on Formann's (1984) rule, the original number of variables (ten) could be too high for data-driven segmentation. Inspection of the items revealed that two items were highly correlated and were very similar in meaning. One of these was consequently omitted for the segmentation analysis. The following final items were included: the possibility that mechanical, equipment, or organizational problems will occur during travel or at the destination (regarding transportation, accommodation, attractions and so on); the possibility that travel experience will not provide value for money; the possibility of becoming sick while traveling or at the destination; the possibility of physical danger or injury detrimental to health (accidents); the possibility of becoming involved in political turmoil in the country being visited; the possibility that travel experience will not provide personal satisfaction; the possibility that travel choice/experience will affect others' opinions of the individual; the possibility of being involved in a terrorist act; and the possibility that the travel experience will take too much time/waste time. These variables were not factor analyzed before conducting the segmentation study, as recommended by Dolnicar and Grün (2008).

\subsection{Analysis}

A post hoc (Myers \& Tauber, 1977), a posteriori (Mazanec, 2000), or data-driven (Dolnicar, 2004) market segmentation was conducted, following the procedure recommended by Dolnicar and Leisch (2010) for data structure analysis before segmenting data. Twenty bootstrap samples were drawn for each number of clusters from two to ten, and independent segmentation analyses were run based on these bootstrap samples. Then, the similarity of resulting solutions was compared within each number of clusters by computing the Rand index (see Fig. 1). Solutions with many instances of returning high Rand indices are more stable and are thus preferable to other solutions. For all analyses the topology representing network algorithm was used, as introduced by Martinetz and Schulten (1994), because simulations with artificial data sets have demonstrated that this algorithm outperforms alternative algorithms concerning identifying the correct data structure in artificial data (Buchta, Dimitriadou, Dolnicar, Leisch, \& Weingessel, 1997).

Once the number of clusters was selected and the final segmentation computations were completed, the resulting segments were compared on the basis of additional personal characteristics. Differences were tested using analyses of variance for metric variables and chi-square tests for nominal and ordinal variables.

\section{Results and discussion}

The respondents were from 41 countries. The sample was mainly composed of men (56\%), and were aged under 35 years (56\%). Approximately 74 percent of respondents were college graduates; 22 percent were middle and senior management; 20 percent were businessmen; approximately 19 percent were freelancers/self-employed; and 15 percent were students. Their average monthly income ranged between 2000 and 3000 euros. The sample was mainly composed of frequent travelers, who had undertaken, on average, seven international trips in the past three years, which each lasted approximately nine days. There was a relatively high degree of familiarity with the destination visited, because tourists had, on average, visited the destination 3.5 times before. Each tourist used on average 15 days to plan the trip and referred to reservation planning of 25 days in advance.

The results of the data structure analysis are provided in Fig. 1. From the boxplot in Fig. 1a, we can see that a two-segment solution is most stable over repeated computations, simply by separating those international travelers who perceived all factors as risky from those who perceived nothing as risky. These have a high average Rand index, as indicated by the horizontal line, and many of the 20 replications achieved high Rand indices, as indicated by the fact that the box for the two-cluster solution is very high. The same can be seen from the density plot in Fig. 1b. However, a two-segment solution does not provide much managerial insight.

The next-best compromise solution is to choose three clusters. At three clusters, reproducibility is still relatively high, although it is not achieved as consistently. We therefore analyze in more detail a

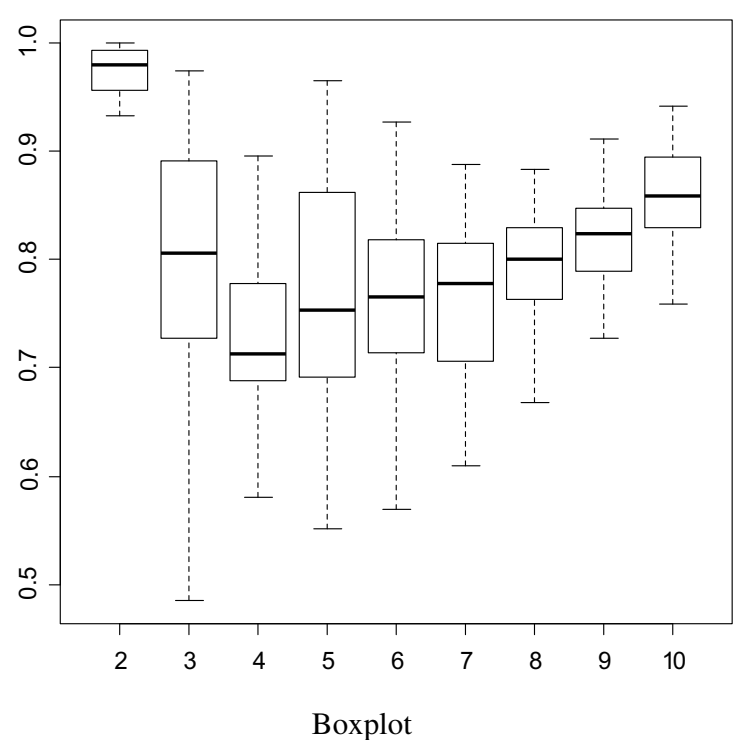

b

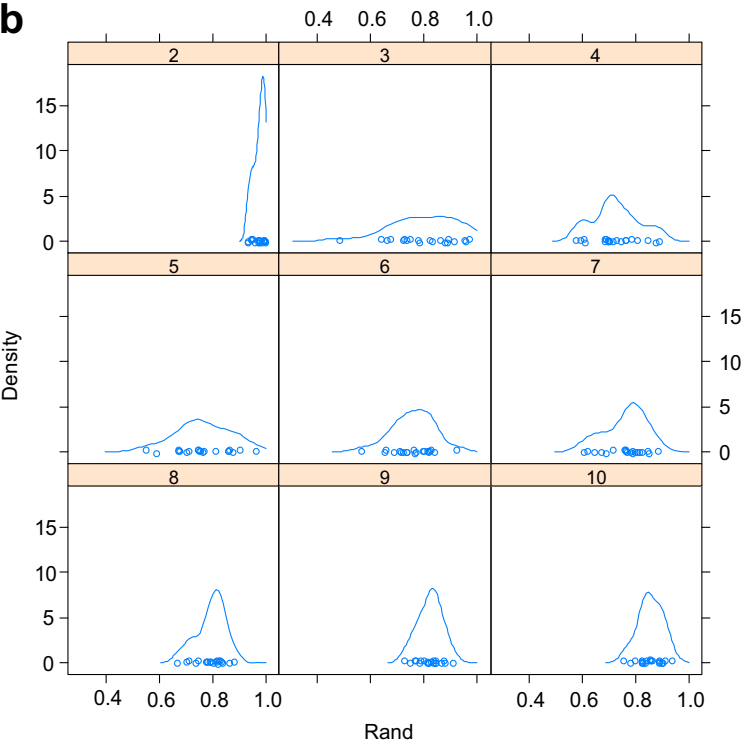

Densityplot

Fig. 1. Results of data structure analysis. 
two solutions: the three-segment solution (Fig. 2), because it provides a split between three groups: those who are not concerned about anything, those who are concerned about everything, and a third group who demonstrated a distinct pattern of concerns.

The weakness of the three-segment solution is that it does not provide detailed insight into smaller segments with particular risk patterns. Therefore, we also selected a seven-segment solution (Fig. 3), which permitted detailed analysis of additional segments of interest. The disadvantage of the seven-segment solution is that the segments with very specific, distinct risk patterns are relatively small, with most comprising between six and 11 percent of the sample.

The following distinct risk patterns emerged from this analysis:

Segment 1: Carefree - representing 45 percent of travelers: this segment does not show major concerns about their trips, and they show a low risk perception in every dimension.

Segment 2: All risks concerned - representing six percent of tourists. This segment has major concerns about their trips, and they show high perceptions of all types of risk.

Segment 3: Satisfaction apprehensive - representing nine percent of travelers. This segment is concerned that they may be dissatisfied, that the travel choice may reflect badly on them and that they may be wasting their time. All these concerns are relatively independent from the destination, as well as from the possibility of external events occurring.

Segment 4: Multiple risks concerned - representing nine percent of tourists. This segment perceives most aspects as riskier than the sample average, except for what other people might think, as well as the risk of dissatisfaction.

Segment 5: Health and personal risks concerned - representing 11 percent. This segment is most concerned about risks to personal health, such as sickness and accidents. They are also concerned about possible problems with equipment or the organization, and that they may not be getting their money's worth.

Segment 6: Terrorism and turmoil - representing 10 percent. This group is very distinct, in that its members are mainly concerned about unpredictable, dangerous events occurring, such as political turmoil or terrorism attacks. This segment is probably the least "crisis proof;" they are likely to cancel their trip or delay a planned vacation if they feel that any such event might occur.

Finally, Segment 7: Materialists - representing 10 percent. This group is concerned more than the average sample about value for money and the organizational matters of the trip.

Several distinct differences in background variables for the seven-segment solution can also be identified. While segments do not differ regarding gender, age, education, or, interestingly, their national and international travel experience, significant differences were found regarding other aspects, namely income, travel motives, contact with crime in everyday life, and nationality.

Segments differ concerning income, with members of Segments 2 and 3 earning the most, and members of Segment 4 earning the least (chi-squared $p$-value $<.001$ ). Segments differ significantly on most of the travel motives. For example, half or more of the members of Segments 4 and 7 indicated that discovering new places was a very important motive for taking a vacation; whereas less than one-third of Segment 6 members agreed with this (chi-squared $p$-value $<.003$ ). The same two segments said that they liked to look for thrills and surprises when on vacation, about one-quarter of each segment rated this motive as extremely important, compared to only 11 percent of Segment 6 (chi-squared $p$-value $<.004)$.

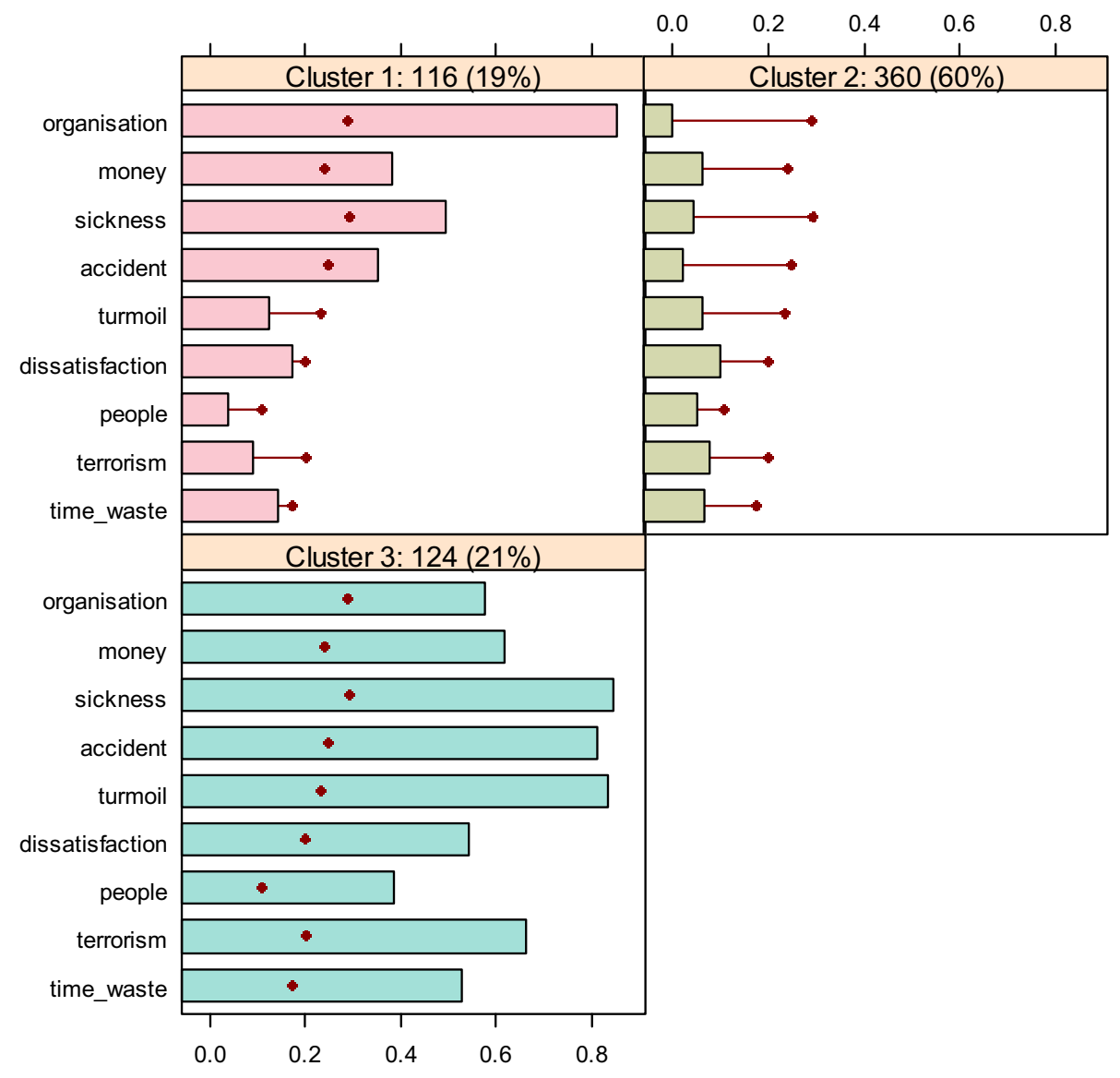

Fig. 2. Profile chart of three-segment solution. 


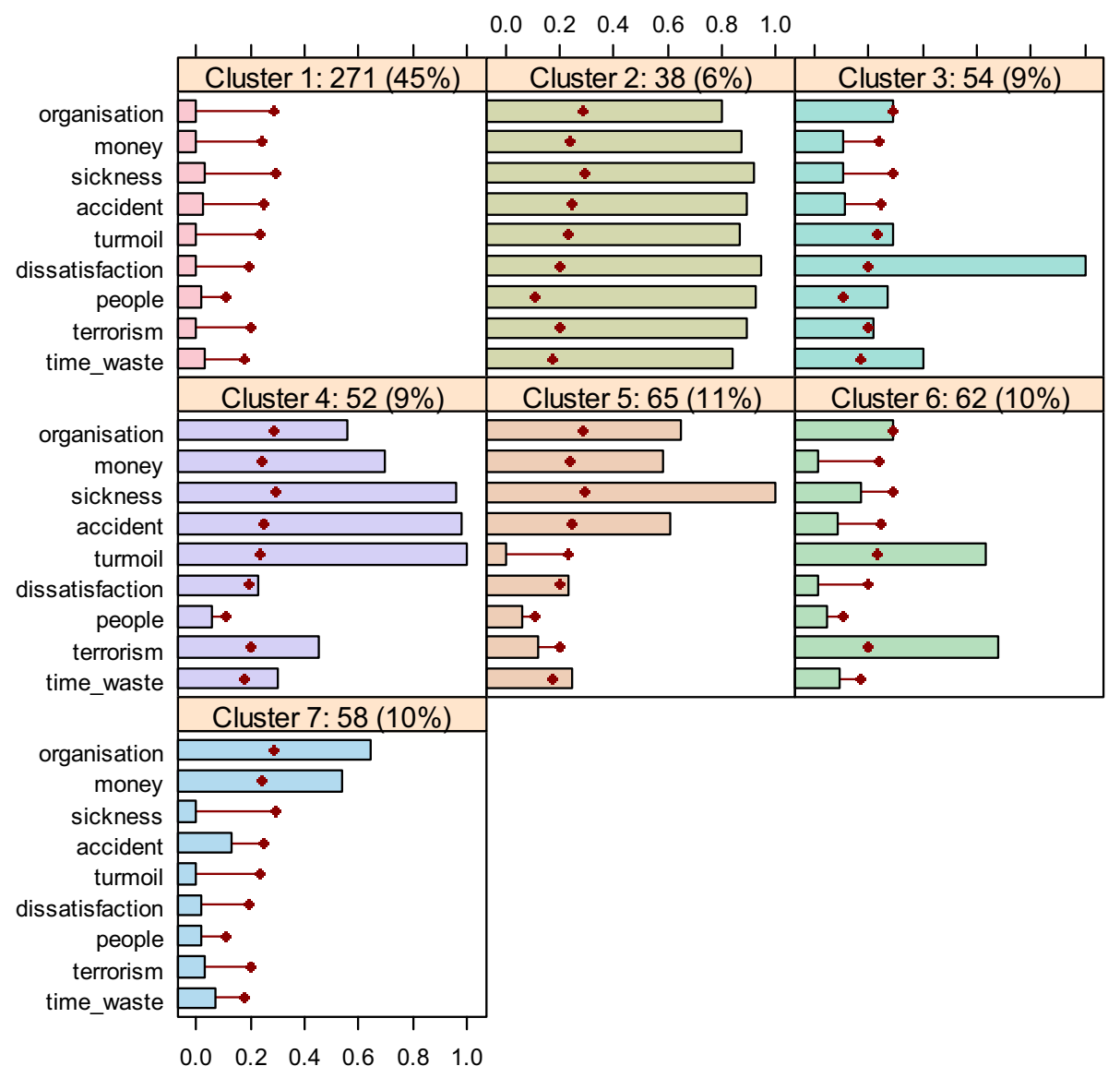

Fig. 3. Profile chart of seven-segment solution.

Significant differences were also identified in the nationality of respondents (chi-squared $p$-value $<.002$ ), which may be analyzed in light of each country's position in Hofstede's (1983) model of cultural dimensions, particularly regarding the dimension designated as "uncertainty avoidance." This is discussed below.

Segment 1, the carefree segment, contains a large proportion of tourists from Germany (11.9\%), Portugal (10\%), and the UK (9.6\%). This is a surprising result, because Germany and Portugal are amongst the countries positioned in the group that has strong uncertainty avoidance, according to the Hofstede index (Hofstede, 1983). However, this finding can be related to the fact that these tourists are visiting locations relatively near their home country, so the risk perception is lower, because they know the reality of the visited destinations (O'Connor, Stafford, \& Gallagher, 2008).

In Segment 2: All risks concerned, the more highly represented nationalities are the US (20.6\%) and Australia (8.8\%), again contradicting Hofstede's index, because these two countries demonstrate a low uncertainty avoidance rating. This result could be explained by the same reasons that operate for Segment 1: that when tourists travel to distant places, far away from their homes, they perceive higher levels of risk. Also, Reisinger and Mavondo (2006) found that tourists from these countries experience relatively more anxiety.

Segment 3: Satisfaction apprehensive are mostly from Portugal (13.5\%), the UK (15.4\%), Brazil (25\%), and Spain (11.5\%), which is an interesting result. Similar results were found for Segment 7: Materialists, comprising Brazilians (20.7\%), Portuguese (12.1\%), Dutch (10.3\%), and British (8.6\%). Interestingly, these nationalities seem to stand out as the most demanding, as far as tourism products are concerned.

Segment 4: Multiple risks concerned is composed mainly of French (18.8\%), Portuguese (15.4\%), British (9.6\%), and Italian (7.7\%) tourists. With the exception of UK tourists, all other nationalities reside in the group that show a strong uncertainty avoidance (Hofstede, 1983), which can explain this fear of multiple risks.

Segment 5: Health and personal risks is composed of French (18.8\%), American (14.1\%), Spanish (12.5\%), and Dutch (10.9\%) tourists, a result that mixes nationalities with different uncertainty avoidance levels and is more difficult to explain, at least by this dimension of Hofstede's model.

On the other hand, Segment 6: Terrorism and turmoil consists of 15 percent tourists from Spain, 13.3 percent from Portugal, 11.7 percent from Germany and 10 percent from Brazil. This can be explained by the fact that tourists from these countries come into contact with crime and terrorism in own their countries (Barker, Page, \& Meyer, 2003; Brunt et al., 2000). The exception is Portugal, but this country may suffer from the neighboring effect of terrorism in Spain.

A number of particularly interesting observations can be made based on the figures in Table 1. Members of Segment 4 had more experience with burglary, physical, or psychological violence or attempted physical or psychological violence compared to the overall sample. This may partly explain the concern that members of Segment 4 expressed about "terrorism" and "turmoil." Furthermore, members of Segment 6 showed a higher level of experience with having been "exposed to a damage site shortly after a terrorist attack" than most other segments, possibly explaining that the only fears members of this segment expressed are related to "turmoil" and "terrorism." On the other hand, members of Segment 2 revealed a general concern regarding diverse risk factors, while most of them had, in actuality, not had any contact with violent events during their holidays previously. These results lead to a hypothesis that 
Table 1

“Crime-experience" levels of segment members (count and percent who never experienced the crime).

\begin{tabular}{|c|c|c|c|c|c|c|c|c|c|}
\hline & & Seg1 & Seg2 & Seg3 & Seg 4 & Seg5 & Seg6 & Seg7 & $p$-Value \\
\hline \multirow[t]{2}{*}{ Burglary } & Count & 188 & 35 & 37 & 29 & 53 & 45 & 43 & \\
\hline & $\%$ & $69.4 \%$ & $92.1 \%$ & $68.5 \%$ & $55.8 \%$ & $81.5 \%$ & $72.6 \%$ & $74.1 \%$ & .005 \\
\hline \multirow[t]{2}{*}{ Physical or psychological violence } & Count & 212 & 33 & 40 & 28 & 47 & 43 & 36 & \\
\hline & $\%$ & $78.2 \%$ & $86.8 \%$ & $74.1 \%$ & $53.8 \%$ & $72.3 \%$ & $69.4 \%$ & $62.1 \%$ & .000 \\
\hline \multirow[t]{2}{*}{ Attempt of physical or psychological violence } & Count & 215 & 33 & 40 & 27 & 50 & 41 & 36 & \\
\hline & $\%$ & $79.3 \%$ & $86.8 \%$ & $74.1 \%$ & $51.9 \%$ & $76.9 \%$ & $66.1 \%$ & $62.1 \%$ & .000 \\
\hline \multirow[t]{2}{*}{ I was present on the scene during a terrorist attack } & Count & 259 & 37 & 47 & 50 & 63 & 55 & 53 & \\
\hline & $\%$ & $95.6 \%$ & $97.4 \%$ & $87.0 \%$ & $96.2 \%$ & $96.9 \%$ & $88.7 \%$ & $91.4 \%$ & .000 \\
\hline \multirow[t]{2}{*}{ I was physically injured by a terrorist attack } & Count & 263 & 37 & 47 & 52 & 63 & 56 & 58 & \\
\hline & $\%$ & $97.0 \%$ & $97.4 \%$ & $87.0 \%$ & $100.0 \%$ & $96.9 \%$ & $90.3 \%$ & $100.0 \%$ & .012 \\
\hline \multirow[t]{2}{*}{ I was exposed to the damaged site shortly after a terrorist attack } & Count & 253 & 37 & 47 & 49 & 61 & 53 & 47 & \\
\hline & $\%$ & $93.4 \%$ & $97.4 \%$ & $87.0 \%$ & $94.2 \%$ & $93.8 \%$ & $85.5 \%$ & $81.0 \%$ & .000 \\
\hline \multirow[t]{2}{*}{ I know somebody who was on site during a terrorist attack } & Count & 248 & 35 & 42 & 45 & 58 & 56 & 45 & \\
\hline & $\%$ & $91.5 \%$ & $92.1 \%$ & $77.8 \%$ & $86.5 \%$ & $89.2 \%$ & $90.3 \%$ & $77.6 \%$ & .003 \\
\hline \multirow[t]{2}{*}{ I escaped a terrorist attack by luck } & Count & 263 & 36 & 45 & 47 & 63 & 55 & 50 & \\
\hline & $\%$ & $97.0 \%$ & $94.7 \%$ & $83.3 \%$ & $90.4 \%$ & $96.9 \%$ & $88.7 \%$ & $86.2 \%$ & .003 \\
\hline
\end{tabular}

cannot be tested with the current data, because personality variables were not tested, but would be worthwhile analyzing in the future. Further studies might examine whether people who are intrinsically fearful express a wider range of fears; whereas people who are not generally fearful, but have experienced crime first hand or through stories told by people close to them, have very specific fears about events of this nature.

\section{Conclusions}

This study provides the first data-driven segmentation study based on tourists' patterns of perceived risks. Results indicate that different groups of tourists exist, revealing different risk perceptions regarding international travel, and these findings support the heterogeneity assumptions made by previous authors (Dolnicar, 2005; Lepp \& Gibson, 2003; Rohel \& Fesenmaier, 1992). Specifically, we found that international tourists can be segmented into seven distinct clusters that differ in the amounts and types of risk perceptions.

Fortunately for the travel industry, the biggest segment, almost half of international travelers, corresponds to a relatively carefree group, who feel no significant risk in any dimension. This is a good target for marketing in times of international tourism crises, because these people do not evidence major concerns about safety. However, the other half of international tourists perceive significant risks when traveling. This group can be equitably divided, between six percent and 11 percent, in six segments with distinctive fears: all risks concerned, satisfaction apprehensive, multiple risks concerned, health and personal risks concerned, terrorism and turmoil concerned and materialists. For these groups it is possible to develop marketing niche strategies.

For all risks and multiple risks concerned, the industry must have a well-developed and well-communicated safety proposal in terms of destination offering and communication/information materials.

For the groups designated as satisfaction apprehensive and materialists, operators and travel agents should prepare travel packages that offer good value for money, which also provide and communicate convincing guarantee schemes.

For the segment concerned with health and personal risks, products must be offered where health and personal integrity are assured; for example, that have medical assistance and health insurance. Also, destination managers should use this market knowledge to pressure the public sector to invest reasonably in health facilities at the destination.

When targeting tourists concerned with terrorism and turmoil, the safety of destinations and tourist infrastructures (lodging, restaurants, and attractions) provided must be a major issue. This segment should probably not be targeted when the terrorist threat at a specific destination is actually relatively high, or is communicated as such in the media. Depending on each destination's reality or image, some of the risk segments might not be the best target, if the occurrence of certain types of events cannot be excluded or dealt with conveniently.

The tourism industry should also consider some of the personal characteristics of its customers, because they influence risk perception and their decision-making processes, namely income, travel motives, previous contact with crime, and nationality.

One interesting result in this study is the impact of nationality on risk perception. Our findings are mostly not explicable by Hofstede's model and do not corroborate other studies using the index of risk avoidance (Kozak et al., 2007). However, even if widely used (for example, Money \& Crotts, 2003), nationality might not be a sufficient indicator of this cultural dimension for a deeper understanding of the phenomenon, and more studies are needed in this field to clarify the issue.

Given the already high complexity of the tourist decisionmaking process, a high risk perception associated with an event that should be pleasant is problematic (Taylor, 2006). Risk and safety perceptions are strong predictors of tourists' choice behaviors (Sönmez \& Graefe, 1998a). Consumer behavior is influenced by safety/risk images that individuals hold about destinations (Sönmez \& Graefe, 1998b). Different levels of safety concerns may influence the evaluation process and subsequent decision-making process. In their decision making, tourists evaluate several factors, especially those relating to safety or risk associated with the tourist destinations. It is also clear that risk perceptions are highly subjective in nature, and frequently do not reflect real risk. Thus, the development of an appropriate marketing strategy is a fundamental part of crisis management.

The segmentation solution identified above may help destination managers to choose more realistically profitable target markets and to cater to their specific needs, while also considering their major concerns and fears when traveling, as well as the real (and media projected) risks of a destination.

The results of this study are limited by the specific context of data collection. The reported research project investigates the risk perceptions of tourists traveling by plane (many of them frequent flyers) regarding terrorism, and care should be taken in extending the study beyond this specific research framework. Additionally, since the data was collected on Fridays, Saturdays and Sundays, the sample may include not only pleasure and regular business travelers, but also "European commuters," professionals who work in another country and travel home every weekend, and this type is mostly insensitive to risk as a job condition. 
The present research is based exclusively on data obtained with self-administrated questionnaires, which can be susceptible to distortion (Schwarz, 1999). However, the advantage of selfadministered surveys is that the respondents do not have to disclose to an interviewer, and can answer sensitive questions related to risk perceptions in a discrete context.

The present study is also limited by its use of nationality as a proxy of Hofstede's value orientations, when some recent research in tourism shows the existence of both subcultures within nationalities and of "international regions," clustering together, "demonstrating that national cultural differences do not end at national borders" (Reisinger \& Crotts, 2010, p. 153). This might indeed have occurred in similar segmentation results for the Spanish, Portuguese, and Brazilian respondents (for example, Segments 3 and 6). For more substantive contributions to the discussion of the role of cultural influences, Hofstede's scale (2001) should probably be used, while a deeper analysis on the role of the other four dimensions of the model on risk perceptions might be worthwhile.

The primary aim of the present study is to explore the heterogeneity among international tourists regarding risk perception patterns. Because data collection was geographically limited, we cannot assume that the resulting segments are universal and generalizable beyond the context of this study. It is also questionable if a single generalizable segmentation solution is realistic; it may be necessary to investigate risk segments specifically for different contexts and tourism services. This is a key direction for future work. Future work could also build on the key insight that substantial heterogeneity exists in the perception of risk by tourists, and other studies may collect more detailed background information from respondents in order to derive much more precise recommendations for destination marketing organizations regarding a suitable marketing mix for different risk segments.

\section{Contributions}

Seabra and Abrantes have collected the empirical data and conducted the literature review along with Kastenholz, Dolnicar has undertaken the data-driven segmentation analysis.

\section{References}

Barker, M., Page, S., \& Meyer, D. (2003). Urban visitor perceptions of safety during a special event. Journal of Travel Research, 41(4), 345-355.

Bauer, R. (1967). Consumer behavior as risk taking. In D. Cox (Ed.), Risk taking and information handling in consumer behavior (pp. 23-33). Cambridge: Harvard University Press.

Beirman, D. (2002). Marketing of tourism destinations during a prolonged crisis: Israel and the Middle East. Journal of Vacation Marketing, 8(2), 167-176.

Beirman, D. (2003). Marketing of tourism destinations during a prolonged crisis: Israel and the Middle East. Journal of Vacation Marketing, 8(3), 167-176.

Brunt, P., Mawby, R., \& Hambly, Z. (2000). Tourist victimization and the fear of crime on holiday. Tourism Management, 21(4), 417-424.

Buchta, C., Dimitriadou, E., Dolnicar, E., Leisch, F., \& Weingessel, A. (1997). A comparison of several cluster algorithms on artificial binary data scenarios from travel market segmentation. Working Paper \#7: SFB "Adaptive Information Systems and Modelling in Economics and Management Science, "Vienna.

Budesco, D., \& Wallstein, T. (1985). Consistency in interpretation of probabilistic phrases. Organizational Behavior and Human Decision Processes, 36(3), 391-405.

Carlsson, F., Johansson-Stenman, O., \& Martinsson, P. (2004). Is transport safety more valuable in the air? Journal of Risk and Uncertainty, 28(2), 147-163.

Chen, J. (1997). The tourists' cognitive decision making model. Tourism Review, 53(1), 4-9.

Cheron, E., \& Ritchie, B. (1982). Leisure activities and perceived risk. Journal of Leisure Research, 14(2), 139-154.

Cohen, E. (1972). Towards a sociology of international tourism. Sociological Research, $39(3), 164-182$

Coshall, J. (2003). The threat of terrorism as an intervention on international travel flows. Journal of Travel Research, 42(1), 4-12.

Crompton, J., \& Ankomah, P. (1993). Choice set propositions in destination decisions. Annals of Tourism Research, 20(3), 461-475.

Crotts, J., \& Erdmann, R. (2002). Does national culture influence consumers evaluation of travel services? A test of Hofstede's model of cross-cultural differences. Managing Service Quality, 10(5), 410-419.
Decrop, A., \& Snelders, D. (2004). Planning the summer vacation - an adaptable process. Annals of Tourism Research, 31(4), 1008-1030.

Dimanche, F., \& Leptic, A. (1999). New Orleans tourism and crime: a case study. Journal of Travel Research, 38(1), 19-23.

Dolnicar, S. (2004). Beyond "commonsense segmentation" - a systematics of segmentation approaches in tourism. Journal of Travel Research, 42(3), 244-250.

Dolnicar, S. (2005). Understanding barriers to leisure travel: tourist fears as a marketing basis. Journal of Vacation Marketing, 11(3), 197-208.

Dolnicar, S. (2007). Crises that scare tourists - investigating tourists' travel-related concerns. In B. Prideaux, B. Laws, \& K. Chon (Eds.), Managing tourism crises (pp. 98-109). London: CABI.

Dolnicar, S., \& Grün, B. (2008). Challenging "factor cluster segmentation". Journal of Travel Research, 47(1), 63-71.

Dolnicar, S., \& Leisch, F. (2010). Evaluation of structure and reproducibility of cluster solutions using the bootstrap. Marketing Letters, 21(1), 83-101.

Dowling, G. (1986). Perceived risk: the construct and its measurement. Psychology and Marketing, 3(3), 193-210.

Élias, N., \& Dunning, E. (2008). Quest for excitement. Sport and leisure in the civilising process. Dublin: University College Dublin Press.

Elsrud, T. (2001). Risk creation in traveling: backpacker adventure narration. Annals of Tourism Research, 28, 597-617.

Eugenio-Martin, J. (2003). Modelling determinants of tourism demand as a fivestage process: a discrete choice methodological approach. Tourism and Hospitality Research, 4(4), 341-354.

Fesenmaier, D. (1988). Integrating activity pattern into destination choice models. Journal of Leisure Research, 20(3), 175-191.

Fletcher, J., \& Morakabati, Y. (2008). Tourism activity, terrorism and political instability within the commonwealth: the cases of Fiji and Kenya. International Journal of Tourism Research, 10(6), 537-556.

Floyd, M., \& Pennington-Gray, L. (2004). Profiling risk perceptions of tourists. Annals of Tourism Research, 31(4), 1051-1054.

Formann, A. (1984). Die Latent-Class-Analuse: Einführung in die Theorie und Anwendung. Weinheim: Beltz.

Fuchs, G., \& Reichel, A. (2006). Correlates of destination risk perception and risk reduction strategies. In M. Kozak, \& L. Andreu (Eds.), Progress in tourism marketing (pp. 161-170). London: Elsevier.

Gemunden, H. (1985). Perceived risk and information search: a systematic metaanalysis of the empirical evidence. International Journal of Research in Marketing, 2, 79-100.

George, R. (2003). Tourists' perceptions of safety and security while visiting Cape Town. Tourism Management, 24(3), 575-585.

Gibson, H., \& Yiannakis, A. (2002). Tourist roles: needs and the adult life course. Annals of Tourism Research, 29(2), 358-383.

Giddens, A. (1991). Modernity and self-identity: Self and society in the late modern age. Stanford, CA: Stanford University Press.

Goodrich, J. (2002). September 11, 2001 attack on America: a record of the immediate impacts and reactions in the USA travel and tourism industry. Tourism Management, 23(6), 573-580.

Gu, Z., \& Martin, T. (1992). Terrorism, seasonality, and international air tourist arrivals in central Florida: an empirical analysis. Journal of Travel and Tourism Marketing, 1(1), 3-15.

Havlena, W., \& DeSarbo, W. (1990). On the measurement of perceived consumer risk. Decision Sciences, 22, 927-939.

Hofstede, G. H. (1980). Culture's consequences: International differences in workrelated values. Beverley Hills, CA: Sage Publications.

Hofstede, G. (1983). The cultural relativity of organizational practices and theories. Journal of International Business Studies, 14(2), 75-89.

Hofstede, G. (2001). Culture's consequences (2nd ed.). Thousand Oaks, CA: Sage.

Huan, T., \& Beaman, J. (2004). Contexts and dynamics of social interaction and information search in decision-making for discretionary travel. Tourism Analysis, 8(2/4), 177-182.

Hugstad, P., Taylor, J., \& Bruce, G. (1987). The effects of social class and perceived risk on consumer information search. Journal of Services Marketing, 1(1), 47-52.

Hurley, J. (1988). The hotels of Rome: meeting the marketing challenge of terrorism. The Cornell Ouarterly, 29(1), 71-79.

Jacoby, J., \& Kaplan, L. (1972). The components of risk perception. In M. Venkatesan (Ed.), Proceedings of the 3rd annual conference (pp. 382-393). Champaign: Association for Consumer Research.

Kaplan, L., Szybillo, G., \& Jacoby, J. (1974). Components of perceived risk in product purchase: a cross-validation. Journal of Applied Psychology, 59(3), 287-291.

Kastenholz, E. (2010). "Cultural proximity" as a determinant of destination image. Journal of Vacation Marketing, 16(4), 313-322.

Kozak, M., Crotts, J., \& Law, R. (2007). The impact of perception of risk on international travellers. International Journal of Tourism Research, 9(4), 233-242.

Lepp, A., \& Gibson, H. (2003). Tourist roles, perceived risk and international tourism. Annals of Tourism Research, 30(3), 606-624.

Levantis, T., \& Gani, A. (2000). Tourism demand and the nuisance of crime. International Journal of Social Economics, 27(7/8/9/10), 959-967.

Levitt, T. (1983). The globalization of marketing. Harvard Business Review, 7. 92-102.

Mansfeld, Y. (1996). Wars, tourism and the "Middle East" factor. In A. Pizam, \& Y. Mansfeld (Eds.), Tourism, crime and international security issues (pp. 265-278). New York: Wiley.

Martinetz, T., \& Schulten, K. (1994). Topology representing networks. Neural Networks, 7(5), 507-522. 
Mazanec, J. (2000). Market segmentation. In J. Jafari (Ed.), Encyclopedia of tourism. London: Routledge.

van Middelkoop, M., Borgers, A., \& Timmermans, H. (2003). Modelling tourist destination choice using a decision table induction algorithm. Environment and Planning, A, 35(9), 1669-1687.

Milman, A., \& Bach, S. (1999). The impact of security devices in tourists' perceived safety: the central Florida example. Journal of Hospitality and Tourism Research, 23(4), 371-386.

Mitchell, V., \& Vassos, V. (1997). Perceived risk and risk reduction in holiday purchases: a cross-cultural and gender analysis. Journal of European Marketing, 6(3), 47-80.

Mitra, K., Reiss, C., \& Capella, L. (1999). An examination of perceived risk, information search and behavioral intentions in search, experience and credences services. Journal of Services Marketing, 13(3), 208-226.

Money, R. B., \& Crotts, J. C. (2003). The effect of uncertainty avoidance on information search, planning, and purchases of international travel vacations. Tourism Management, 24(2), 191-202.

Moutinho, L. (1987). Consumer behavior in tourism. European Journal of Marketing, 21(10), 5-44.

Moutinho, L. (2000). Consumer behavior. In L. Moutinho (Ed.), Strategic development in tourism (pp. 41-79). New York: CABI Publishing.

Mueller, R. D., Palmer, A., Mack, R., \& McMullan, R. (2003). Service in the restaurant industry: an American and Irish comparison of service failures and recovery strategies. International Journal of Hospitality Management, 22(4), 395-418.

Murray, K., \& Schlater, J. (1990). The impact of services versus goods on consumers assessment of perceived risk and variability. Journal of Academy of Marketing Science, 18(1), 51-65.

Myers, J., \& Tauber, E. (1977). Market structure analysis. Chicago: American Marketing Association.

Nerhagen, L. (2003). Travel mode choice: effects of previous experience on choice behaviour and valuation. Tourism Economics, 9(1), 5-30.

O'Connor, N., Stafford, M., \& Gallagher, G. (2008). The impact of global terrorism on Ireland's tourism industry: an industry in perspective. Tourism and Hospitality Research, 8(4), 351-364.

Pizam, A. (2002). Tourism and terrorism. International Journal of Hospitality Management, 21(1), 1-3.

Pizam, A., \& Mansfeld, Y. (1996). Tourism, crime and international security issues. Chichester: Wiley.

Prideaux, B. (1996). The tourism crime cycle: a beach destination case study. In A. Pizam, \& Y. Mansfeld (Eds.), Tourism, crime and international security issues (pp. 77-90). London: John Wiley and Sons.

Quintal, V., Lee, J., \& Soutar, G. (2010). Risk, uncertainty and the theory of planned behavior: a tourism example. Tourism Management, 31(6), 797-805.

Reisinger, Y., \& Crotts, J. C. (2010). Applying Hofstede's national culture measures in tourism research: illuminating issues of divergence and convergence. Journal of Travel Research, 49(2), 153-164.

Reisinger, Y., \& Mavondo, F. (2005). Travel anxiety and intentions to travel internationally: implications of travel risk perception. Journal of Travel Research, 43(3), 212-225.

Reisinger, Y., \& Mavondo, F. (2006). Cultural differences in travel risk perception. Journal of Travel and Tourism Marketing, 20(1), 13-31.

Ritchie, B. (2004). Chaos, crises and disasters: a strategic approach to crisis management in the tourism industry. Tourism Management, 25(6), 669-683.

Rittichainuwat, B., \& Chakraborty, G. (2009). Perceived travel risks regarding terrorism and disease: the case of Thailand. Tourism Management, 30(3), 410-418.

Rohel, W., \& Fesenmaier, D. (1992). Risk perceptions and pleasure travel: an exploratory analysis. Journal of Travel Research, 2(4), 17-26.

Roselius, T. (1971). Consumer ranking of risk-reduction methods. Journal of Marketing, 31(1), 56-61.

Schwarz, N. (1999). Self-reports: how the questions shape the answers. American Psychologist, 54, 93-105.

Seabra, C., Abrantes, J., \& Lages, L. (2007). The impact of external information sources in expectations formation and future use of media. Tourism Management, 28(6), 1541-1554.

Seddighi, H., Nuttall, M., \& Theocharous, A. (2001). Does cultural background of tourists influence the destination choice? An empirical study with special reference to political instability. Tourism Management, 22(2), 181-191.

Sönmez, S. (1998). Tourism, terrorism and political instability. Annals of Tourism Research, 25(2), 416-456.

Sönmez, S., \& Graefe, A. (1998a). Influence of terrorism risk on foreign tourism decisions. Annals of Tourism Research, 25(1), 112-144.

Sönmez, S., \& Graefe, A. (1998b). Determining future travel behavior from past travel experience and perceptions of risk and safety. Journal of Travel Research, 37(4), 171-177.
Stone, R., \& Gronhaug, K. (1993). Perceived risk: further considerations for the marketing discipline. European Journal of Marketing, 27(3), 39-50.

Taylor, P. (2006). Getting them to forgive and forget: cognitive based marketing responses to terrorist acts. International Journal of Tourism Research, 8, 171-183.

Tsaur, S., Tzeng, G., \& Wang, K.-C. (1997). Evaluating tourist risks from fuzzy perspectives. Annals of Tourism Research, 24(4), 796-812.

Woodside, A., \& King, R. (2001). An updated model of travel and tourism purchaseconsumption systems. Journal of Travel and Tourism Marketing, 10(1), 3-27.

Woodside, A., \& Lysonski, A. (1989). A general model of traveler destinations choice. Journal of Travel Research, 27(4), 8-14.

Yavas, U. (1990). Correlates of vacation travel: some empirical evidence. Journal of Professional Services Marketing, 5(2), 3-18.

Zeithaml, V. (1981). How consumer evaluation processes differ between goods and services. In J. Donelly, \& W. George (Eds.), Marketing of services (pp. 186-190). Chicago: American Marketing Association.

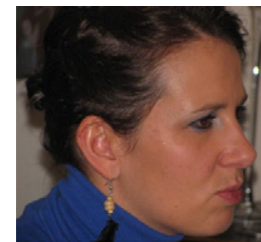

Claudia Seabra, is Associate Professor at the Polytechnic Institute of Viseu - Higher School of Technology and Management. She has publications in the Journal of Business Research, Tourism Management and a chapter in the Scientific Book Marketing Innovations for Sustainable Destinations. She is affiliated with the Portuguese Foundation for Science and Technology and Center for Studies in Education, Technologies and Health. Claudia Seabra develops her research in: 1) services marketing, 2) tourism, e 3) pedagogy.

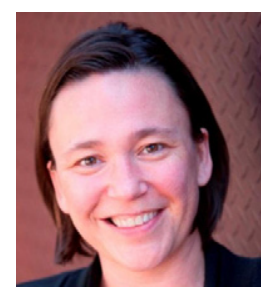

Sara Dolnicar is a Professor of Marketing at the University of Wollongong in Australia and the Director of the Institute for Innovation in Business and Social Research (IIBSoR). Sara's key research interests are measurement in the socia sciences and market segmentation methodology, primarily applied to the field of tourism.

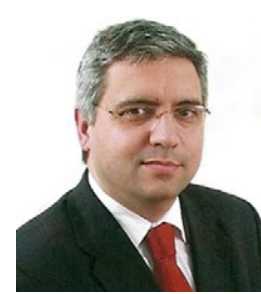

José Luís Abrantes is Professor in Polytechnic Institute of Viseu - Higher School of Technology and Management. He has publications in Journal of Business Research, Tourism Management, International Marketing Review, among other journals. He is affiliated with the Portuguese Foundation for Science and Technology and Center for Studies in Education, Technologies and Health. Jose Luis Abrantes develops his research in: 1) marketing, 2) tourism, and 3) pedagogy.

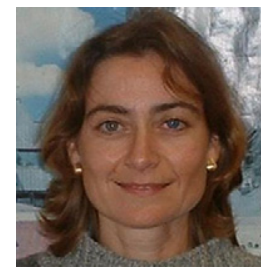

Elisabeth Kastenholz is Assistant Professor at the Aveiro University; Department of Economics, Management and Industrial Engineering; member of the research unit of Governance, Competitiveness and Public Policies (GOVCOPP); she currently coordinates the master's degree in Tourism Management and Planning at the University of Aveiro and a research project on the integral rural tourism experience; with publications in the Journal of Travel Research, Tourism Economics, Journal of Sustainable Tourism, Journal of Vacation Marketing and Anatolia, in numerous international conference proceedings and several book chapters; her research focuses on rura tourism, consumer behavior in tourism, destination marketing and sustainable destination development. 